\title{
Influence of serotonergic/noradrenergic gene polymorphisms on nausea and sweating induced by milnacipran in the treatment of depression
}

This article was published in the following Dove Press journal:

Neuropsychiatric Disease and Treatment

13 July 2009

Number of times this article has been viewed

\author{
Hisashi Higuchi' \\ Hitoshi Takahashi ${ }^{2}$ \\ Mitsuhiro Kamata ${ }^{3}$ \\ Keizo Yoshida ${ }^{4}$ \\ 'Department of Psychiatry, \\ St. Marianna University, School \\ of Medicine, Kanagawa, Japan; \\ ${ }^{2}$ Department of Psychiatry, Tokyo \\ Women's Medical University, School \\ of Medicine, Tokyo, Japan; \\ ${ }^{3}$ Department of Psychiatry, \\ Yuri-Kumiai General Hospital, \\ Yuri-Honjo, Akita, Japan; ${ }^{4}$ Department \\ of Psychiatry, Nagoya University \\ School of Medicine, Aichi, Japan
}

\begin{abstract}
The present study was conducted to find out the predictors of side effects such as nausea and excessive sweating induced by milnacipran, a serotonin/norepinephrine reuptake inhibitor. Both clinical characteristics prior to the treatment and gene polymorphisms such as serotonin transporter (5-HTT) gene-linked polymorphic region (5-HTTLPR), a variable number of tandem repeats in the second intron of the 5-HTT gene (5-HTTVNTR), 5-HT2A receptor gene (5-HT2A G-1438A), a TPH gene polymorphism in intron 7 (TPH A218C), norepinephrine transporter (NET) gene polymorphism in the promoter region (NET T-182C) and in the exon 9 (NET G1287A), a variable number of tandem repeats in the promoter region of monoamine oxidase A, were items to be assessed in this study. Ninety-six patients with major depressive disorder were treated with milnacipran. Side effects were assessed at 1, 2, 4, and 6 weeks of treatment with Udvalg for Kliniske Undersogelser side effects scale. The results showed that no gene polymorphisms included in this study affected the susceptibility of nausea and excessive sweating induced by milnacipran. Patients with older age are more likely to develop excessive sweating than others. The major limitation of this study is a small sample size. Further studies with larger populations and more kinds of gene polymorphisms should be needed to see if specific gene polymorphisms determine the susceptibility of side effects induced by milnacipran.
\end{abstract}

Keywords: milnacipran, nausea, excessive sweating, gene polymorphisms

\section{Introduction}

Adverse events are common even in the newer antidepressant drugs, such as selective serotonin reuptake inhibitors (SSRIs) and dual serotonin/norepinephrine reuptake inhibitors (SNRIs), which have been reported to possess higher tolerance compared to tricyclic antidepressants (TCAs). ${ }^{1,2}$ Adverse events of antidepressants have been reported to be the most common reasons for poor adherence to antidepressant therapy, resulting in high relapse rates. ${ }^{3}$ Thus careful attention should be paid to adverse events not only in the early phase of the treatment but also during maintenance after remission.

Knowledge of predictive factors can help to minimize the incidence of adverse events with antidepressants. Certain gene polymorphisms related to serotonin neurotransmission appear to be predictive of sensitivity to the adverse events of SSRI antidepressants. ${ }^{4-6}$ To our knowledge, however, there are no reports investigating the predictive factors for adverse events induced by SNRI antidepressants such as venlafaxine, milnacipran, or duloxetine. In this study, we examined the possible association between adverse events induced by the SNRI, milnacipran, and gene polymorphisms related to serotonergic or noradrenergic neurotransmission. We focused on seven polymorphisms: 1) the serotonin transporter (5-HTT) gene-linked polymorphic region
Correspondence: Hitoshi Takahashi Department of Psychiatry, Tokyo Women's Medical University, 8-I Kawada-cho, Shinjuku-ku, Tokyo, 162-8666, Japan

$\mathrm{Tel}+8 \mathrm{I} 333538 \mathrm{III}$

Email takahashi_h1969@yahoo.co.jp 
(5-HTTLPR); 2) the variable number of tandem repeats in the second intron of the 5-HTT gene (5-HTTVNTR); 3) the 5-HT2A receptor gene (5-HT2A G-1438A); 4) the tryptophan hydroxylase (TPH) gene polymorphism in intron 7 (TPH A218C); 5) the norepinephrine transporter (NET) gene polymorphism in the promoter region (NET T-182C) and 6) in the exon 9 (NET G1287A); and 7) the variable number of tandem repeats in the promoter region of monoamine oxidase A (MAOA-VNTR). The aim of this study is to investigate whether polymorphisms of specific genes affect the occurrence of adverse events induced by the SNRI, milnacipran.

\section{Methods}

\section{Subjects and treatment}

Patients meeting the DSM-IV diagnosis of major depressive disorder and who scored 20 or more on the Montgomery and Asberg Depression Rating Scale (MADRS) ${ }^{7}$ were included in this study. Patients with other Axis I disorders or with Axis II disorders were excluded by clinical assessment based on The Mini-International Neuropsychiatric Interview. The patients were 20-69 years of age and free of psychotropic drugs for at least 14 days before entry into the study. Milnacipran was administered twice daily (the same dose after dinner and at bedtime) for six weeks. We have two reasons for our choice of administration time. One reason is that the elimination half-life of milnacipran is not long. Therefore, we need to give it to the patients separately. Another reason is that the daytime medication has to be omitted for the accurate assessment of steady-state plasma milnacipran concentration. The initial total daily dose was $50 \mathrm{mg} /$ day and after one week it was increased to $100 \mathrm{mg} /$ day, which is the recommended dose in Japan. ${ }^{8,9}$ Patients with insomnia were prescribed brotizolam $(0.25$ or $0.5 \mathrm{mg})$, a benzodiazepine sedative hypnotic. No other psychotropic drugs were permitted during the study.

\section{Assessment}

Adverse events were assessed using the Udvalg for Kliniske Undersogelser (UKU) side effects scale, which developed to provide a comprehensive side effect rating scale with well-defined and operationalized items to assess the side effects of psychopharmacological medications. ${ }^{10}$ Depression symptom severity was assessed using the MADRS and a clinical response was defined as a $50 \%$ or greater decrease from baseline at the endpoint (or at the time when patients withdraw from the study in the case of early termination). The assessments of adverse events and treatment response were conducted at baseline and 1, 2, 4, and 6 weeks after initiation of milnacipran. A single rater conducted all ratings for each patient. If patients had certain "adverse event-like" symptoms before the start of the milnacipran treatment, these symptoms were not subsequently counted as adverse events. Because patients with major depression often complain of somatic symptoms, very mild symptoms of which total UKU scale change was equal to or less than 1 over the whole study period were excluded for adverse event profile.

\section{Blood samples for quantification of plasma milnacipran concentration and genotyping}

Blood samples were collected 12 hours after drug administration at bedtime, four weeks after initiation of milnacipran treatment, for both genotyping and measurement of plasma milnacipran concentration. Details of the analytical method have been described previously. ${ }^{11}$ Genotyping was performed for the polymorphisms described below.

5-HTT gene-linked polymorphism (5-HTTLPR), a variable number of tandem repeats in the second intron of the 5-HTT gene (5-HTTVNTR), a G-1438A polymorphism in the promoter region of the 5-HT2A receptor gene (5-HT2A G-1438A) and a TPH gene polymorphism in intron 7 (TPH A218C) were determined as described previously. ${ }^{12-15}$

Both of the NET gene polymorphisms in the promoter region (T-182C) and in the exon 9 (G1287A) were determined as described by Jonsson and colleagues. ${ }^{16}$

A variable number of tandem repeats in the promoter region of MAOA gene (MAOA-VNTR) was determined by Yoshida and colleagues. ${ }^{6}$

\section{Statistical analysis}

Differences in clinical characteristics between subjects with and without nausea, or between subjects with and without sweating were analyzed with the use of the unpaired $t$-test or chi-square test where appropriate. Plasma milnacipran concentrations were also analyzed with the use of unpaired $t$-test. A p value lower than 0.05 was considered to be statistically significant in the above analysis.

Genotype distributions of each polymorphisms in patients with and without side effects were analyzed with the use of the chi-square test and Bonferroni corrections applied for multiple testing. The Bonferroni procedure uses a powerful family-wise error-rate controlling. However, the power to detect a specific hypothesis is reduced when the number of hypotheses in the family increases. Therefore, in our association analysis here, overall statistical significant level was 
set to 0.1 . Hence, the family-wise error-rate after Bonferroni corrections was $0.007(0.1 / 14)$. We excluded MAOA VNTR group from the statistical analysis because of violation of Hardy-Weinberg equilibrium.

The Ethics Committee of Akita University School of Medicine approved this study. All subjects received a full explanation of the study and only those who gave written consent to participate were enrolled in the study.

\section{Results}

\section{Characteristics of patients}

Ninety-six patients were initially recruited. Of these 16 patients were excluded from the study for the following reasons; one patient withdrew from the study because of acute deterioration of depressive symptoms, four patients stopped visiting our hospital without explanation, six patients were considered to have poor compliance, showing very low milnacipran concentrations, and five patients refused genetic sampling. No patients withdrew from the study due to side effects. A total of 80 patients: 52 women and 28 men, 49 outpatients and 31 inpatients, aged 25-69 years (mean age \pm $\mathrm{SD}=52.4 \pm 14.3$ ), were included in the statistical analysis.

\section{Adverse events and treatment response induced by milnacipran}

Table 1 shows the incidence of side effects in this study. Of 80 patients, $30(37.5 \%)$ developed adverse events. Of those

Table I Adverse events induced by milnacipran treatment $(\mathrm{N}=80)$

\begin{tabular}{lll}
\hline & Number of patients & (\%) \\
\hline Nausea & 10 & 12.5 \\
Increased sweating & 10 & 12.5 \\
Headache & 7 & 8.8 \\
Constipation & 5 & 6.3 \\
Palpitation & 4 & 5.0 \\
Dry mouth & 3 & 3.8 \\
Discomfort of head & 3 & 3.8 \\
Chill or heat of leg or arms & 3 & 3.8 \\
Sleep disturbance & 2 & 2.5 \\
Bitterness & $\mathrm{I}$ & 1.3 \\
Inner tension/anxiety & $\mathrm{I}$ & 1.3 \\
Blurred vision & $\mathrm{I}$ & 1.3 \\
Stomach ache & $\mathrm{I}$ & 1.3 \\
Urinary hesitancy & $\mathrm{I}$ & 1.3 \\
Tremor & $\mathrm{I}$ & 1.3 \\
Diarrhea & $\mathrm{I}$ & 1.3 \\
Skin tingling & $\mathrm{I}$ & 1.3 \\
\hline
\end{tabular}

30 patients, 20 had only a single side effect while the remaining 10 experienced two or more different adverse events.

Mean MADRS scores dropped significantly from $28.6 \pm$ 5.4 (mean $\pm \mathrm{SD}$ ) to $12.4 \pm 9.1$ (mean $\pm \mathrm{SD}$ ) during the study period $(p<0.05)$. Fifty out of 80 patients $(62.5 \%)$ were considered as responders at the end of the study. No significant associations were found between treatment response and incidence of any adverse effects (data not shown).

\section{Predictive factors of side effects}

We focused on nausea and sweating, which were two principal adverse events, developing in more than $10 \%$ of patients taking milnacipran in this study. Only one patient developed both nausea and sweating.

\section{Nausea}

Table 2 shows the clinical characteristics in patients with and without nausea. No clinical characteristics at baseline affected the development of nausea induced by milnacipran. Plasma milnacipran concentrations in patients with and without nausea were similar $(90.7 \pm 39.2 \mathrm{ng} / \mathrm{ml}$ and $91.8 \mathrm{ng} / \mathrm{ml}$, respectively). Table 3 shows genotype distributions in patients with and without nausea. There were no significant differences in genotype distributions of any polymorphism between patients with and without nausea.

\section{Excessive sweating}

Table 4 shows clinical characteristics in patients with and without excessive sweating. There was a statistical significant difference $(\mathrm{p}=0.03)$ in the mean age of the two groups (patients with sweating: $59.6 \pm 7.9$ years; patients with no sweating: $50.3 \pm 12.3$ years). No other clinical characteristics differed significantly between the two groups. Mean plasma concentrations of milnacipran were similar $(89.4 \pm 40.3 \mathrm{ng} / \mathrm{ml}$ and $93.1 \pm 37.3 \mathrm{ng} / \mathrm{ml}$ in patients with and without excessive sweating, respectively). Table 5 shows that no significant

Table 2 Clinical characteristic of patients with and without nausea $(\mathrm{N}=80)$

\begin{tabular}{llll}
\hline & $\begin{array}{l}\text { Nausea }(+) \\
(\mathbf{N}=10)\end{array}$ & $\begin{array}{l}\text { Nausea }(-) \\
(\mathbf{N}=\mathbf{7 0})\end{array}$ & P value \\
\hline Sex (male/female) & $5 / 5$ & $25 / 49$ & $\mathrm{P}=0.3 \mathrm{I}$ \\
Age $\left(\right.$ year) $^{\mathrm{a}}$ & $53.4 \pm 14.7$ & $51.1 \pm 11.9$ & $\mathrm{P}=0.59$ \\
Number of previous episodes $^{\mathrm{a}}$ & $0.1 \pm 0.3$ & $0.4 \pm 1.1$ & $\mathrm{P}=0.42$ \\
Melancholia $( \pm)_{\text {MADRS score at baseline }}$ & $2 / 8$ & $22 / 48$ & $\mathrm{P}=0.7 \mathrm{I}$ \\
\hline
\end{tabular}

Notes: a Data are expressed as mean \pm SD. A p value lower than 0.05 is defined as statistically significant. 
Table 3 Genotype distributions in patients with and without nausea $(\mathrm{N}=80)$

\begin{tabular}{|c|c|c|c|c|}
\hline \multirow{2}{*}{$\frac{\text { Group }}{5-H T T \text { LPR }}$} & \multicolumn{3}{|c|}{ Genotype distribution (N) } & \multirow[t]{2}{*}{$p$ value } \\
\hline & & & & \\
\hline & $S / S$ & $S / L$ & $\mathrm{~L} / \mathrm{L}$ & \\
\hline Nausea $(+)$ & 5 & 4 & 0 & $\chi^{2}=0.70$ \\
\hline Nausea (-) & 46 & 23 & 2 & $P=0.70$ \\
\hline \multicolumn{5}{|c|}{ 5-HTT VNTR } \\
\hline & $12 / 12$ & $12 / 10$ & $10 / 10$ & \\
\hline Nausea $(+)$ & 7 & 2 & 0 & $\chi^{2}=0.49$ \\
\hline Nausea (-) & 58 & 11 & 2 & $p=0.78$ \\
\hline \multicolumn{5}{|c|}{ 5-HT2A G-1438A } \\
\hline & $\mathrm{A} / \mathrm{A}$ & $\mathrm{G} / \mathrm{A}$ & $\mathrm{G} / \mathrm{G}$ & \\
\hline Nausea $(+)$ & 2 & 5 & 2 & $\chi^{2}=0.48$ \\
\hline Nausea (-) & 22 & 31 & 18 & $P=0.78$ \\
\hline \multicolumn{5}{|c|}{ MAOA VNTR } \\
\hline & $1 / 1$ & $1 / 3$ & $3 / 3$ & \\
\hline Nausea $(+)$ & 7 & 0 & 2 & $(-)$ \\
\hline Nausea (-) & 35 & 17 & 17 & $(-)$ \\
\hline \multicolumn{5}{|l|}{ TPH A2। $8 \mathrm{C}$} \\
\hline & $\mathrm{A} / \mathrm{A}$ & $\mathrm{A} / \mathrm{C}$ & $\mathrm{C} / \mathrm{C}$ & \\
\hline Nausea $(+)$ & 2 & 6 & I & $\chi^{2}=1.7$ \\
\hline Nausea $(-)$ & 19 & 32 & 20 & $P=0.42$ \\
\hline \multicolumn{5}{|l|}{ NET T-I82C } \\
\hline & $T / T$ & $\mathrm{~T} / \mathrm{C}$ & $\mathrm{C} / \mathrm{C}$ & \\
\hline Nausea $(+)$ & 3 & 5 & 1 & $\chi^{2}=0.43$ \\
\hline Nausea $(-)$ & 27 & 40 & 4 & $\mathrm{p}=0.80$ \\
\hline \multicolumn{5}{|c|}{ NET GI287A } \\
\hline & $\mathrm{G} / \mathrm{G}$ & $\mathrm{G} / \mathrm{A}$ & $\mathrm{A} / \mathrm{A}$ & \\
\hline Nausea (+) & 6 & 3 & 0 & $\chi^{2}=1.9$ \\
\hline Nausea (-) & 32 & 32 & 7 & $p=0.38$ \\
\hline
\end{tabular}

Notes: MAOA VNTR was excluded from analysis because of violation of HardyWeinberg equilibrium. A p value lower than 0.007 is defined as statistically significant (see text for detail).

differences were found in genotype distributions of each polymorphism between patients with and without excessive sweating. No significant differences were also found on age among each genotype in each polymorphism (data not shown).

\section{Discussion}

A major limitation of this study is the small number of patients for genetic study. This limitation drastically decreases the power and therefore increases the possibility of a false positive finding. More patients should have been assessed to increase the accuracy of the study results. To our knowledge, however, this is the first study aimed to find out the predictor of side effects induced by an SNRI. We think the results of this study are worth reporting.

The present study indicated that no association was found between gene polymorphisms assessed in this study
Table 4 Clinical characteristics of the patients with and without sweating $(\mathrm{N}=80)$

\begin{tabular}{llll}
\hline & $\begin{array}{l}\text { Sweating }(+) \\
(\mathbf{N}=10)\end{array}$ & $\begin{array}{l}\text { Sweating }(-) \\
(\mathbf{N}=\mathbf{7 0})\end{array}$ & p value \\
\hline $\begin{array}{l}\text { Sex (male/female) } \\
\text { Age (year) }\end{array}$ & $4 / 6$ & $24 / 46$ & $\mathrm{P}=0.73$ \\
$\begin{array}{l}\text { Number of previous } \\
\text { episodes }^{\mathrm{a}}\end{array}$ & $59.6 \pm 7.9$ & $50.3 \pm 12.3$ & $*_{\mathrm{p}=0.03}$ \\
$\begin{array}{l}\text { Melancholia (+/-) } \\
\begin{array}{l}\text { MADRS score } \\
\text { at baseline }\end{array}\end{array}$ & $3 / 7$ & $0.39 \pm 1.1 \mathrm{I}$ & $\mathrm{P}=0.87$ \\
\end{tabular}

Notes: ${ }^{\mathrm{D}} \mathrm{Data}$ are expressed as mean $\pm \mathrm{SD}$. *A p value lower than 0.05 is defined as statistically significant.

and milnacipran-induced side effects such as nausea and excessive sweating. Each adverse event is reported to be associated mainly with stimulation of serotonergic and noradrenergic neurotransmission, respectively. Some researchers including ourselves have reported the possible interactions between serotonergic gene polymorphisms and incidence of SSRI-induced nausea. ${ }^{4-6}$ However, we did not find any serotonergic gene polymorphisms that were related to milnacipran-induced nausea. These differences in the results may come from the differences in pharmacological profiles between SSRI and SNRI. Exact mechanism of this difference, however, is unknown.

Excessive sweating is a common adverse effect of many antidepressant medications. The rates of this incidence have been reported in $10 \%$ of patients taking SSRIs, $14 \%$ of patients taking TCAs and $12 \%-14 \%$ of patients taking the SNRI, venlafaxine, which are in accordance with the rate of $11.8 \%$ in this study. ${ }^{17-20}$ Some reports indicated that noradrenalin is involved with the mechanisms of excessive sweating induced by antidepressants. ${ }^{21,22}$ Therefore, there is a possibility that gene polymorphisms related to noradrenalin neurotransmitter function have some association with excessive sweating induced by milnacipran. So far, no report described the relationship between antidepressant-induced sweating and gene polymorphisms. Although our study is the first report in this field, the results could not detect any association between noradrenergic gene polymorphisms and milnacipran-induced excessive sweating. In order to increase the chance to find out the specific genes related to this side effect, a larger sample size and more different kinds of gene polymorphisms are need to be analyzed.

The data also showed that patients in older age had higher susceptibility to milnacipran-induced excessive sweating. This finding suggests that caution should be taken to avoid 
Table 5 Genotype distributions in patients with and without excessive sweating $(\mathrm{N}=80)$

\begin{tabular}{|c|c|c|c|c|}
\hline \multirow{2}{*}{$\frac{\text { Group }}{5-\mathrm{HTT} \text { LPR }}$} & \multicolumn{3}{|c|}{ Genotype distribution (N) } & \multirow[t]{2}{*}{ p value } \\
\hline & & & & \\
\hline & $\mathrm{S} / \mathrm{S}$ & $S / L$ & $\mathrm{~L} / \mathrm{L}$ & \\
\hline Sweating $(+)$ & 2 & 6 & I & $\chi^{2}=8.5$ \\
\hline Sweating (-) & 48 & 22 & 1 & $P=0.013$ \\
\hline \multicolumn{5}{|l|}{ 5-HTT VNTR } \\
\hline & $12 / 12$ & $12 / 10$ & $10 / 10$ & \\
\hline Sweating $(+)$ & 6 & 3 & 0 & $\chi^{2}=2.3$ \\
\hline Sweating (-) & 59 & 10 & 2 & $P=0.31$ \\
\hline \multicolumn{5}{|c|}{ 5-HT2A G-I438A } \\
\hline & $\mathrm{A} / \mathrm{A}$ & $\mathrm{G} / \mathrm{A}$ & G/G & \\
\hline Sweating $(+)$ & 3 & 2 & 4 & $\chi^{2}=2.7$ \\
\hline Sweating (-) & 21 & 34 & 16 & $P=0.25$ \\
\hline \multicolumn{5}{|c|}{ MAOA VNTR } \\
\hline & $\mathrm{I} / \mathrm{I}$ & $1 / 3$ & $3 / 3$ & \\
\hline Sweating $(+)$ & 5 & 2 & 2 & $(-)$ \\
\hline Sweating (-) & 37 & 15 & 17 & $(-)$ \\
\hline \multicolumn{5}{|l|}{ TPH A2I8C } \\
\hline & $\mathrm{A} / \mathrm{A}$ & $\mathrm{A} / \mathrm{C}$ & $\mathrm{C} / \mathrm{C}$ & \\
\hline Sweating $(+)$ & 2 & 5 & 2 & $\chi^{2}=0.26$ \\
\hline Sweating (-) & 19 & 33 & 19 & $\mathrm{p}=0.87$ \\
\hline \multicolumn{5}{|l|}{ NETT-I82C } \\
\hline & $\mathrm{T} / \mathrm{T}$ & $\mathrm{T} / \mathrm{C}$ & $\mathrm{C} / \mathrm{C}$ & \\
\hline Sweating $(+)$ & I & 8 & 0 & $\chi^{2}=4.4$ \\
\hline Sweating (-) & 29 & 37 & 5 & $\mathrm{P}=0.10$ \\
\hline \multicolumn{5}{|l|}{ NET GI 287A } \\
\hline & $\mathrm{G} / \mathrm{G}$ & $\mathrm{G} / \mathrm{A}$ & $\mathrm{A} / \mathrm{A}$ & \\
\hline Sweating $(+)$ & 4 & 5 & 0 & $\chi^{2}=1.2$ \\
\hline Sweating (-) & 34 & 30 & 7 & $P=0.54$ \\
\hline
\end{tabular}

Notes: MAOA VNTR was excluded from analysis because of violation of HardyWeinberg equilibrium. A p value lower than 0.007 is defined as statistically significant (see text for detail).

this side effect when prescribing milnacipran in patients with older age. The underlying reason why older patients are susceptible to this side effect is unknown.

Morishita and colleague ${ }^{23}$ suggested that in patients who were aged 50 or older, milnacipran had a tendency to be more effective than fluvoxamine and paroxetine. Age may be associated not only with treatment response but also the side effects of milnacipran.

The findings from this study should be taken as preliminary. Information from more kind of gene polymorphisms with larger population are needed to see if specific gene polymorphisms determine the susceptibility of side effects induced by milnacipran.

\section{Acknowledgments}

This study was supported in part by a grant from the Ministry of Education, Culture, Sports, Science and Technology of Japan. After completion of the study and its analysis,
Asahi-Kasei Pharma, manufacturers of milnacipran in Japan, accepted to support the publication of the study with an unconditional educational grant. They played no role in the interpretation of the dada, in writing the manuscript or in the submission of the paper for publication. The authors thank Dr. Mike Briley for his assistance in correcting the manuscript. All authors declare that they have no conflicts of interest in relation to the subject of this manuscript.

\section{References}

1. Anderson IM. Meta-analytical studies on new antidepressants. Br Med Bull. 2001;57:161-178.

2. Stahl SM, Grady MM, Moret C, Briley M. SNRIs: their pharmacology, clinical efficacy, and tolerability in comparison with other classes of antidepressants. CNS Spectr. 2005;10:732-747.

3. Mitchell AJ. Depressed patients and treatment adherence. Lancet. 2006;367(9528):2041-2043.

4. Kato M, Fukuda T, Wakeno M, et al. Effects of the serotonin type 2A, $3 \mathrm{~A}$ and $3 \mathrm{~B}$ receptor and the serotonin transporter genes on paroxetine and fluvoxamine efficacy and adverse drug reactions in depressed Japanese patients. Neuropsychobiology. 2006;53:186-195.

5. Sugai T, Suzuki Y, Sawamura K, Fukui N, Inoue Y, Someya T. The effect of 5-hydroxytryptamine $3 \mathrm{~A}$ and $3 \mathrm{~B}$ receptor genes on nausea induced by paroxetine. Pharmacogenomics J. 2006;6:351-356.

6. Yoshida K, Naito S, Takahashi H, et al. Monoamine oxidase A gene polymorphism, 5-HT 2A receptor gene polymorphism and incidence of nausea induced by fluvoxamine. Neuropsychobiology. 2003;48:10-13.

7. Montgomery SA, Asberg M. A new depression scale designed to be sensitive to change. Br J Psychiatry. 1979;134:382-389.

8. Sugawara Y, Higuchi H, Yoshida K, et al. Response rate obtained using milnacipran depending on the severity of depression in the treatment of major depressive patients. Clin Neuropharmacol. 2006;29:6-9.

9. Tajima O. Japanese experience with dual-action antidepressants. Int Clin Psychopharmacol. 2002;17(Suppl 1):S37-S42.

10. Lingjaerde O, Ahlfors UG, Bech P, Dencker SJ, Elgen K. The UKU side effect rating scale. A new comprehensive rating scale for psychotropic drugs and a cross-sectional study of side effects in neuroleptic-treated patients. Acta Psychiatr Scand. 1987;334:1-100.

11. Higuchi H, Yoshida K, Takahashi H, et al. Milnacipran plasma levels and antidepressant response in Japanese major depressive patients. Hum Psychopharmacol. 2003;18:255-259.

12. Ito K, Yoshida K, Sato K, et al. A variable number of tandem repeats in the serotonin transporter gene does not affect the antidepressant response to fluvoxamine. Psychiatry Res. 2002;111:235-239.

13. Sato K, Yoshida K, Takahashi H, et al. Association between -1438G/A promoter polymorphism in the 5-HT(2A) receptor gene and fluvoxamine response in Japanese patients with major depressive disorder. Neuropsychobiology. 2002;46:136-140.

14. Yoshida K, Ito K, Sato K, et al. Influence of the serotonin transporter gene-linked polymorphic region on the antidepressant response to fluvoxamine in Japanese depressed patients. Prog Neuropsychopharmacol Biol Psychiatry. 2002;26:383-386.

15. Yoshida K, Naito S, Takahashi H, et al. Monoamine oxidase: A gene polymorphism, tryptophan hydroxylase gene polymorphism and antidepressant response to fluvoxamine in Japanese patients with major depressive disorder. Prog Neuropsychopharmacol Biol Psychiatry. 2002;26:1279-1283.

16. Jonsson EG, Nothen MM, Gustavsson JP, et al. Polymorphisms in the dopamine, serotonin, and norepinephrine transporter genes and their relationships to monoamine metabolite concentrations in CSF of healthy volunteers. Psychiatry Res. 1998;79:1-9.

17. Marcy TR, Britton ML. Antidepressant-induced sweating. Ann Pharmacother. 2005;39:748-752. 
18. Package insert. Lexapo (escitalopram oxalate). St. Louis, MO: Forest Pharmaceuticals; August 2004.

19. Trindade E, Menon D, Topfer LA, Coloma C. Adverse effects associated with selective serotonin reuptake inhibitors and tricyclic antidepressants: a meta-analysis. CMAJ. 1998;159:1245-1252.

20. Wickersham RM. Drug and comparisons 2004. 58th ed. St. Louis, MO: Wolters Kluwer Health; 2003. p. 1024-1071.
21. Butt MM. Managing antidepressant-induced sweating. J Clin Psychiatry. 1989;50:146-147.

22. Leeman CP. Pathophysiology of tricyclic-induced sweating. J Clin Psychiatry. 1990;51:258-259.

23. Morishita S, Arita S. Differential effects of fluvoxamine, paroxetine and milnacipran for depression, especially with regard to age. Hum Psychopharmacol. 2004;19:405-408.

\section{Publish your work in this journal}

Neuropsychiatric Disease and Treatment is an international, peerreviewed journal of clinical therapeutics and pharmacology focusing on concise rapid reporting of clinical or pre-clinical studies on a range of neuropsychiatric and neurological disorders. This journal is indexed on PubMed Central, the 'PsycINFO' database and CAS, and is the official

journal of The International Neuropsychiatric Association (INA). The manuscript management system is completely online and includes a very quick and fair peer-review system, which is all easy to use. Visit http://www.dovepress.com/testimonials.php to read real quotes from published authors.

Submit your manuscript here: http://www.dovepress.com/neuropsychiatric-disease-and-treatment-journal 